\title{
IDH2 NM_002168.3:c.515_516delGGinsAA
}

National Cancer Institute

\section{Source}

National Cancer Institute. IDH2 NM 002168.3:C.515 516de/GGinsAA. NCI Thesaurus.

Code C131111.

A complex substitution where the nucleotide sequence at positions 515 and 516 of the coding sequence of the IDH1 gene has changed from guanine-guanine to adenineadenine. 